\title{
Biofield Treatment: An Alternative Approach to Combat Multidrug-Resistant Susceptibility Pattern of Raoultella ornithinolytica
}

\author{
Mahendra Kumar Trivedi ${ }^{1}$, Shrikant Patil ${ }^{1}$, Harish Shettigar ${ }^{1}$, Mayank Gangwar ${ }^{2}$ and Snehasis Jana ${ }^{2^{*}}$ \\ ${ }^{1}$ Trivedi Global Inc., 10624 S Eastern Avenue Suite A-969, Henderson, NV 89052, USA \\ ${ }^{2}$ Trivedi Science Research Laboratory Pvt. Ltd, Madhya Pradesh, India
}

*Corresponding author: Jana S, Trivedi Science Research Laboratory Pvt. Ltd, Fortune City, Hoshangabad Rd., Bhopal, Madhya Pradesh, India, Tel: +91-755-6660006; E-mail: publication@trivedisrl.com

Received date: June 6, 2015, Accepted date: July 23, 2015, Published date: July 30, 2015

Copyright: $\odot$ 2015, Trivedi MK et al. This is an open-access article distributed under the terms of the Creative Commons Attribution License, which permits unrestricted use, distribution, and reproduction in any medium, provided the original author and source are credited.

\begin{abstract}
Raoultella ornithinolytica is belongs to the family of Enterobacteriaceae, a Gram-negative encapsulated aerobic bacillus associated with bacteremia and urinary tract infections. As biofield therapy is increasingly popular in biomedical heath care, so present study aimed to evaluate the impact of Mr. Trivedi's biofield treatment on antimicrobial sensitivity, minimum inhibitory concentration (MIC), biochemical study, and biotype number of multidrug resistant strain of $R$. ornithinolytica. Clinical sample of $R$. ornithinolytica was divided into two groups i.e. control and biofield treated which were analyzed for the above parameters using MicroScan Walk-Away® system on day 10 after treatment. Antimicrobial sensitivity assay results showed a significant increase $(60.71 \%)$ in sensitivity pattern of antimicrobials i.e. changed from resistant to susceptible while $10.71 \%$ of tested antimicrobials changed from intermediate to susceptible as compared to control. MIC results showed a significant decrease in MIC values of $71.88 \%$ tested antimicrobials as compared to control.

Biochemical reaction study showed $15.15 \%$ alteration in different biochemical such as cetrimide, cephalothin, kanamycin, and ornithine after biofield treatment as compared to control. A significant change in biotype number (7775 4370) was also observed with organism identified as Klebsiella oxytoca after biofield treatment as compared to control (7775 5372). Overall results conclude that biofield treatment could be used as complementary and alternative treatment strategy against multidrug resistant strain of $R$. ornithinolytica with respect to improve the sensitivity and reduce the MIC values of antimicrobials. Hence, it is assumed that biofield treatment might be a suitable cost effective treatment strategy in near future, which could have therapeutic value in patients suffering from multidrug resistant pathogens.
\end{abstract}

Keywords: Raoultella ornithinolytica; Biofield treatment; Antimicrobial susceptibility; Biochemical reaction; Biotype; Multidrug resistant

\section{Introduction}

Genus Raoultella belongs to the family Enterobacteriaceae, mainly contains Gram-negative, aerobic, non-motile, capsulated, and facultative anaerobic bacilli [1]. Initially, genus Raoultella was classified in Klebsiella, further on the basis of $16 \mathrm{~S}$ rRNA and rpoB genes study includes it in new genus Raoultella. It includes Raoultella ornithinolytica, $R$. electrica, $R$. planticola, and $R$. terrigena. $R$. ornithinolytica is widely distributed in aquatic flora, fishes and insects, but it was associated with histamine poisoning in fish [2]. Human infections are often less reported earlier, but different cases of bacteremia are reported due to $R$. terrigena [3], $R$. planticola [4] and $R$. ornithinolytica $[5,6]$.

Although most of the infectious cases are often associated with underlying existing infection especially malignancies. However, other pathogenic cases such as urinary tract infection, soft issue infections in adults and neonatal infections are also reported [7]. Thus, this is very clear from the above reports that Raoultella genus acts as human pathogen and multidrug resistant (MDR) strain will cause a serious threat to human health causing pneumonia and other infections [8]. Broad spectrum antimicrobials and combinations therapies are the only treatment strategy to cure the infection of MDR. Antimicrobials are always associated with serious side effects [9]. Currently, no such alternative therapies apart from medicines are available against MDR microorganism infections, biofield treatment may be a new approach to improve the susceptibility pattern of $R$. ornithinolytica.

The National Center for Complementary and Alternative Medicine (NCCAM) places biofield therapy under subcategory of energy therapies as one of the five complementary medicine domain. It is scientifically preferred term for the biologically produced electromagnetic and subtle energy field that provides regulatory and communication functions within the organism. The cumulative effect of bio-magnetic and electric field that surrounds the human body is defined as biofield energy. However, the energy can exists in several forms such as kinetic, potential, electrical, magnetic, and nuclear. But human body has the power to produce measurable electric and magnetic signals $[10,11]$.

Similarly, the human nervous system consists of the energy and chemical information in the form of electrical signals. Thus, human has the ability to harness the energy from environment or universe and can transmit into any living or nonliving object(s) around the globe. The objects always receive the energy and responding into useful way via biofield energy and the process is known as biofield treatment. Even every cell of human body will produce minute amount of magnetic and electric field, as it always covers with positive 
Page 2 of 6

and negative charge in outer and inner cell wall respectively [12]. The biofield energy can be monitored by using electromyography (EMG), electrocardiography (ECG) and electroencephalogram (EEG) [13]. Mr. Trivedi's biofield treatment is well known and significantly studied in different fields such as altering the sensitivity pattern of different human pathogens [14-16]. It has been significantly studied in field of agriculture [17-19], biotechnology [20,21], and in material science [22-24].

\section{Materials and Methods}

\section{Experimental design and biofield treatment}

MDR strain of $R$. ornithinolytica was obtained from stored stock cultures of clinical sample in Microbiology Lab, Hinduja Hospital, Mumbai. MDR strain was divided in two groups i.e. control and treatment. In case of treatment group, sealed pack of MDR strain of $R$. ornithinolytica was handed over to Mr. Trivedi for biofield treatment under laboratory conditions. Mr. Trivedi provided the treatment through his energy transmission process to the treated group without touching the sample. The biofield treated sample was returned in the similar sealed condition and further analyzed on day 10 using the standard protocols. After biofield treatment, following parameters like antimicrobial susceptibility, MIC values, biochemical reactions, and biotype number were measured using MicroScan Walk-Away ${ }^{\oplus}$ system (Dade Behring Inc., USA) with respect to control. All antimicrobials and biochemicals were procured from Sigma Aldrich.

\section{Evaluation of antimicrobial susceptibility assay}

Antimicrobial susceptibility pattern of $R$. ornithinolytica was studied using MicroScan Walk-Away system along with Negative Break Point Combo (NBPC 30) panel as per manufacturer's instructions. The antimicrobial susceptibility pattern (S: Susceptible, I: Intermediate, and R: Resistant) and minimum inhibitory concentration (MIC) values were determined by observing the lowest antimicrobial concentration showing growth inhibition. The antimicrobials used in the susceptibility assay viz. amikacin, amoxicillin/k-clavulanate, ampicillin/sulbactam, ampicillin, aztreonam, cafazolin, cefepime, cefotaxime, cefotetan, cefoxitin, ceftazidime, ceftriaxone, cefuroxime, cephalothin, chloramphenicol, ciprofloxacin, ESBL-a Scrn, ESBL-b Scrn, gatifloxacin, gentamicin, imipenem, levofloxacin, meropenem, moxifloxacin, nitrofurantoin, norfloxacin, piperacillin, piperacillin/tazobactam, tetracycline, ticarcillin/k-clavulanate, and tobramycin, trimethoprim/ sulfamethoxazole [25].

\section{Biochemical study}

Biochemical study of $R$. ornithinolytica was determined using MicroScan Walk-Away system in both control and treated groups. Biochemicals used in the study are acetamide, adonitol, arabinose, arginine, cetrimide, cephalothin, citrate, colistin, esculin hydrolysis, nitrofurantoin, glucose, hydrogen sulfide, indole, inositol, kanamycin, lysine, malonate, melibiose, nitrate, oxidation-fermentation, galactosidase, ornithine, oxidase, penicillin, raffinose, rhaminose, sorbitol, sucrose, tartarate, tryptophan deaminase, tobramycin, urea, and Voges-Proskauer [25].

\section{Identification by biotype number}

The biotype number of $R$. ornithinolytica in control and treated samples were determined followed by identification of microorganism by MicroScan Walk-Away processed panel report with the help of biochemical reaction data [25].

\section{Results}

\section{Antimicrobial susceptibility}

Results of antimicrobial sensitivity pattern and MIC values of control and biofield treated MDR strain of $R$. ornithinolytica are summarized in Tables 1 and 2, respectively. All these changes were observed on day 10 after the biofield treatment as compared to control group. Antimicrobial sensitivity assay showed that $60.71 \%$ of tested 28 antimicrobials were reported with significant increase in sensitivity pattern from $\mathrm{R} \rightarrow \mathrm{S}$ viz. amoxicillin/k-clavulanate, ampicillin/ sulbactam, aztreonam, cefazolin, cefotaxime, ceftriaxone, cefuroxime, cephalothin, ciprofloxacin, gatifloxacin, gentamicin, levofloxacin, moxifloxacin, piperacillin, tetracycline, trimethoprim/ sulfamethoxazole, and tobramycin after biofield treatment. Apart from this, $10.71 \%$ tested antimicrobials showed altered sensitivity pattern from I $\rightarrow \mathrm{S}$ in ceftazidime, piperacillin/tazobactam, and ticarcillin/kclavulanate as compared to control. Rest of the antimicrobials (28.7\%) did not show any alteration in sensitivity pattern (Table 1 ).

\begin{tabular}{|c|c|c|c|}
\hline S. No. & Antimicrobial & Control & Treated \\
\hline 1 & Amikacin & $\mathrm{S}$ & $S$ \\
\hline 2 & Amoxicillin/k-clavulanate & $\mathrm{R}$ & $\mathrm{S}$ \\
\hline 3 & Ampicillin/sulbactam & $\mathrm{R}$ & $\mathrm{S}$ \\
\hline 4 & Ampicillin & $\mathrm{R}$ & $\mathrm{R}$ \\
\hline 5 & Aztreonam & $\mathrm{R}$ & $S$ \\
\hline 6 & Cefazolin & $\mathrm{R}$ & $S$ \\
\hline 7 & Cefepime & S & S \\
\hline 8 & Cefotaxime & $\mathrm{R}$ & $\mathrm{S}$ \\
\hline 9 & Cefotetan & $\mathrm{S}$ & $\mathrm{S}$ \\
\hline 10 & Cefoxitin & $S$ & $\mathrm{~S}$ \\
\hline 11 & Ceftazidime & 1 & $\mathrm{~S}$ \\
\hline 12 & Ceftriaxone & $\mathrm{R}$ & $\mathrm{S}$ \\
\hline 13 & Cefuroxime & $\mathrm{R}$ & $S$ \\
\hline 14 & Cephalothin & $\mathrm{R}$ & $\mathrm{S}$ \\
\hline 15 & Chloramphenicol & $S$ & $S$ \\
\hline 16 & Ciprofloxacin & $\mathrm{R}$ & $\mathrm{S}$ \\
\hline 17 & Gatifloxacin & $\mathrm{R}$ & $\mathrm{S}$ \\
\hline 18 & Gentamicin & $\mathrm{R}$ & $\mathrm{S}$ \\
\hline 19 & Imipenem & S & $S$ \\
\hline 20 & Levofloxacin & $\mathrm{R}$ & $\mathrm{S}$ \\
\hline
\end{tabular}


Citation: $\quad$ Trivedi MK, Patil S, Harish S, Gangwar M, Jana S (2015) Biofield Treatment: An Alternative Approach to Combat Multidrug-Resistant Susceptibility Pattern of Raoultella ornithinolytica. Altern Integr Med 4: 193. doi:10.4172/2327-5162.1000193

Page 3 of 6

\begin{tabular}{|l|c|c|c|}
\hline 21 & Meropenem & S & S \\
\hline 22 & Moxifloxacin & R & S \\
\hline 23 & Piperacillin & R & S \\
\hline 24 & Piperacillin/tazobactam & I & S \\
\hline 25 & Tetracycline & R & S \\
\hline 26. & Ticarcillin/k-clavulanate & I & S \\
\hline 27. & Tobramycin & R & S \\
\hline 28. & Trimethoprim/sulfamethoxazole & R & S \\
\hline & R: Resistant; I: Intermediate; S: Susceptible \\
\hline
\end{tabular}

Table 1: Effect of biofield treatment on Raoultella ornithinolytica to antimicrobial susceptibility.

Besides antimicrobial sensitivity assay, an overall significant decrease in MIC values were reported in $71.88 \%$ of antimicrobials (twenty three out of thirty two) against $R$. ornithinolytica as compared to control. Four folds decreased in MIC value were observed in case of cefotaxime, ceftriaxone, piperacillin, piperacillin/tazobactam, ticarcillin/k-clavulanate, and cefuroxime while two folds decreased in MIC value in case of amoxicillin/clavulanic acid, ampicillin/sulbactam, aztreonam, cefazolin, cephalothin, ceftazidime, gentamicin, norfloxacin, tetracycline, tobramycin, gatifloxacin, levofloxacin, moxifloxacin, and ciprofloxacin. Trimethoprim/sulfamethoxazole was reported with decreased MIC value (less than $2 / 38 \mu \mathrm{g} / \mathrm{mL}$ ) as compared to control (Figure 1 and Table 2).

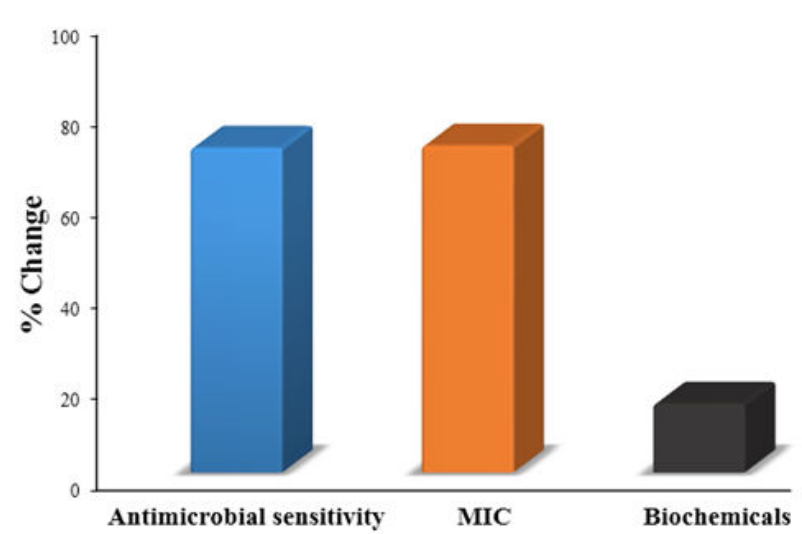

Figure 1: Percentage change in antimicrobial sensitivity pattern, minimum inhibitory concentration (MIC) values and biochemical reactions after biofield treatment of multidrug resistant strain of Raoultella ornithinolytica.

\begin{tabular}{|c|l|l|l|}
\hline S. No. & Antimicrobial & $\begin{array}{l}\text { Control } \\
(\boldsymbol{\mu g} / \mathrm{mL})\end{array}$ & $\begin{array}{l}\text { Treated } \\
(\boldsymbol{\mu g} / \mathrm{mL})\end{array}$ \\
\hline 1 & Amikacin & $\leq 16$ & $\leq 16$ \\
\hline 2 & Amoxicillin/k-clavulanate & $>16 / 8$ & $\leq 8 / 4$ \\
\hline 3 & Ampicillin/sulbactam & $>16 / 8$ & $\leq 8 / 4$ \\
\hline
\end{tabular}

\begin{tabular}{|c|c|c|c|}
\hline 4 & Ampicillin & $>16$ & $>16$ \\
\hline 5 & Aztreonam & $>16$ & $\leq 8$ \\
\hline 6 & Cefazolin & $>16$ & $\leq 8$ \\
\hline 7 & Cefepime & $\leq 8$ & $\leq 8$ \\
\hline 8 & Cefotaxime & $>32$ & $\leq 8$ \\
\hline 9 & Cefotetan & $\leq 16$ & $\leq 16$ \\
\hline 10 & Cefoxitin & $\leq 8$ & $\leq 8$ \\
\hline 11 & Ceftazidime & 16 & $\leq 8$ \\
\hline 12 & Ceftriaxone & $>32$ & $\leq 8$ \\
\hline 13 & Cefuroxime & $>16$ & $\leq 4$ \\
\hline 14 & Cephalothin & $>16$ & $\leq 8$ \\
\hline 15 & Chloramphenicol & $\leq 8$ & $\leq 8$ \\
\hline 16 & Ciprofloxacin & $>2$ & $\leq 1$ \\
\hline 17 & ESBL-a Scrn & $>4$ & $\leq 4$ \\
\hline 18 & ESBL-b Scrn & $>1$ & $\leq 1$ \\
\hline 19 & Gatifloxacin & $>4$ & $\leq 2$ \\
\hline 20 & Gentamicin & $>8$ & $\leq 4$ \\
\hline 21 & Imipenem & $\leq 4$ & $\leq 4$ \\
\hline 22 & Levofloxacin & $>4$ & $\leq 2$ \\
\hline 23 & Meropenem & $\leq 4$ & $\leq 4$ \\
\hline 24 & Moxifloxacin & $>4$ & $\leq 2$ \\
\hline 25 & Nitrofurantoin & $\leq 32$ & $\leq 32$ \\
\hline 26 & Norfloxacin & $>8$ & $\leq 4$ \\
\hline 27 & Piperacillin & $>64$ & $\leq 16$ \\
\hline 28 & Piperacillin/tazobactam & 64 & $\leq 16$ \\
\hline 29 & Tetracycline & $>8$ & $\leq 4$ \\
\hline 30 & Ticarcillin/k-clavulanate & 64 & $\leq 16$ \\
\hline 31 & Tobramycin & $>8$ & $\leq 4$ \\
\hline 32 & Trimethoprim/sulfamethoxazole & $>2 / 38$ & $\leq 2 / 38$ \\
\hline
\end{tabular}

Table 2: Minimum inhibitory concentration (MIC) of tested antimicrobials on Raoultella ornithinolytica.

\section{Biochemical reaction}

Table 3 summarizes the data related to biochemical reactions in control and biofield treated group. Results showed that, $15.15 \%$ tested biochemical reactions out of 33 were changed from positive (+) to negative (-) such as cetrimide, cephalothin, kanamycin, ornithine, and tobramycin after biofield treatment as compared with control (Figure $1)$. 
Page 4 of 6

\begin{tabular}{|c|c|c|c|c|}
\hline S. No. & Code & Biochemical & Control & Treated \\
\hline 1 & ACE & Acetamide & - & - \\
\hline 2 & ADO & Adonitol & + & + \\
\hline 3 & ARA & Arabinose & + & + \\
\hline 4 & ARG & Arginine & - & - \\
\hline 5 & CET & Cetrimide & + & - \\
\hline 6 & CF8 & Cephalothin & + & - \\
\hline 7 & $\mathrm{CIT}$ & Citrate & + & + \\
\hline 8 & CL4 & Colistin & - & - \\
\hline 9 & ESC & Esculin hydrolysis & + & + \\
\hline 10 & FD64 & Nitrofurantoin & - & - \\
\hline 11 & GLU & Glucose & + & + \\
\hline 12 & $\mathrm{H} 2 \mathrm{~S}$ & Hydrogen sulfide & - & - \\
\hline 13 & IND & Indole & + & + \\
\hline 14 & INO & Inositol & + & + \\
\hline 15 & K4 & Kanamycin & + & - \\
\hline 16 & LYS & Lysine & + & + \\
\hline 17 & MAL & Malonate & + & + \\
\hline 18 & MEL & Melibiose & + & + \\
\hline 19 & NIT & Nitrate & + & + \\
\hline 20 & OF/G & Oxidation-Fermentation & + & + \\
\hline 21 & ONPG & Galactosidase & + & + \\
\hline 22 & ORN & Ornithine & + & - \\
\hline 23 & OXI & Oxidase & - & - \\
\hline 24 & P4 & Penicillin & + & + \\
\hline 25 & RAF & Raffinose & + & + \\
\hline 26 & RHA & Rhaminose & + & + \\
\hline 27 & SOR & Sorbitol & + & + \\
\hline 28 & SUC & Sucrose & + & + \\
\hline 29 & TAR & Tartrate & - & - \\
\hline 30 & TDA & Tryptophan Deaminase & - & - \\
\hline 31 & TO4 & Tobramycin & + & - \\
\hline 32 & URE & Urea & + & + \\
\hline 33 & VP & Voges-Proskauer & + & + \\
\hline
\end{tabular}

\section{Organism identification by biotype number}

Based on the biochemical results, change in biotype number was observed in biofield treated group (7775 4370) at day 10 of $R$. ornithinolytica with respect to control (7775 5372). After alteration in biotype number the new organism was identified as Klebsiella oxytoca (Table 4).

\begin{tabular}{|l|l|l|}
\hline Feature & Control & Treated \\
\hline Biotype & 77755372 & 77754370 \\
\hline $\begin{array}{l}\text { Organism } \\
\text { Identification }\end{array}$ & Raoultella ornithinolytica & Klebsiella oxytoca \\
\hline
\end{tabular}

Table 4: Effect of biofield treatment on Raoultella ornithinolytica to distinguishing feature of the genotype.

\section{Discussion}

MDR emergence of $R$. ornithinolytica is a global health problem commonly associated with bacteremia, urinary tract infection, neonatal infections, and exist in underlying existing infection $[6,26,27]$. Increasing resistance in microorganism for antimicrobials becomes a major threat to health and economic problem which ultimately leads to allowing survival of the resistant bacteria and death of the susceptible ones. Major mechanistic pathways associated with resistant in microorganism are cell membrane alterations, which lead to decreased uptake of drug [28]; mutation occurs, that lead to over expression of drug target enzymes and the other common mechanism being the drug efflux pump [29]. Now-a-days, $R$. ornithinolytica acquired resistance against broad range of antimicrobials. Research study suggests that most of the clinical isolates of $R$. ornithinolytica were found resistant to all class of antimicrobials such as ampicillin, amoxicillin, cephalothin, cephotaxime, chloramphenicol, penicillin, gentamicin, rifampin, and streptomycin. Nitrofurantoin and meropenam showed highest sensitivity for $R$. ornithinolytica in all the clinical samples [30]. Our experimental control sample $(R$. ornithinolytica) showed similar sensitivity and resistant pattern of tested antimicrobials. Overall results showed increase in antimicrobial sensitivity after biofield treatment in $71.4 \%$ tested antimicrobials as compared to control. Mr. Trivedi's biofield treatment has significantly decreased the MIC values of $71.87 \%$ tested antimicrobials as compared to control. As an enteric pathogen, $R$. ornithinolytica causes enteric fever associated with syndrome like fever, headache, and abdominal pain. Best treatment therapy during the infection starts with amoxicillin/clavulanic acid for 10-14 days, but therapy depends upon the sensitivity pattern of clinical strain [31]. Different class of antimicrobials showed significant effect after biofield treatment viz. $\beta$ Lactam penicillins (amoxicillin/clavulanic acid, ampicillin/sulbactam, and piperacillin), cephalosporins (cefazolin, ceftriaxone, and cefuroxime), monobactum (azetronan), fluoroquinolones (ciprofloxacin and levofloxacin), aminoglycosides (amikacin and tobramycin) and tetracycline. Lucchetti et al. studied the effect of energy therapy as an alternate medicine on growth of bacterial culture, and found a significant effect [32]. Similarly, experimental results showed improved antimicrobial sensitivity and reduced MIC values suggest that biofield treatment could be a new alternative treatment approach to inhibit the growth of pathogenic bacteria.

Several phenotypic biochemical identification tests were available to differentiate the Raoultella species. Identification test of $R$. ornithinolytica was performed using a series of biochemical reactions 
and the basic positive reactions were observed in case of urea, ornithine and lysine decarboxylase, citrate, glucose, and sucrose. It generally grown at $10^{\circ} \mathrm{C}$ with utilization of L-sorbose as a carbon source [33]. Experimental control group showed positive reaction in above general characteristic of $R$. ornithinolytica, but biofield treatment group showed a significant alteration i.e. negative reactions in biochemical such as cetrimide, cephalothin, kanamycin, ornithine and tobramycin. Further, these biochemical changes were studied by biotype number analysis which was performed using an automated system. A significant changed in biotype number was found in treated group on day 10, and new organism was identified as Klebsiella oxytoca after biofield treatment as compared to control $R$. ornithinolytica (Table 4). Biofield treatment on pathogenic microorganism had been reported, which alter the biochemical reactions, followed by change biotype number and identification of new microorganism after treatment. Current results are well supported with recent reported study [34].

Overall results of antimicrobial assay suggest that Mr. Trivedi's biofield treatment has significantly improved the sensitivity and MIC value of most of the tested antimicrobials (Figure 1). Therefore, it may be possible that lower dose of antimicrobials might require with similar response after biofield treatment, which may minimize the side effects associated with higher doses of antimicrobials. Mr. Trivedi has the ability to harness energy from environment and altered the significant changes in microorganisms $[15,16]$. Biofield treatment might be responsible to do alteration in microorganism at genetic level and/or enzymatic level, which may act on receptor protein. While altering receptor protein, ligand-receptor/protein interactions may alter that could lead to show different phenotypic characteristics. Biofield treatment might induce significant changes in MDR strain of $R$. ornithinolytica, so that tested antimicrobials were showed better susceptibility pattern, decreased MIC values, and altered biochemical reactions, against this microorganism.

\section{Conclusion}

Present study concludes that biofield treatment has the ability to inhibit the microbial growth, by significantly increasing the susceptibility pattern and decreasing the MIC values of $71 \%$ tested antimicrobials. Biofield treatment has significantly altered the biochemical reactions and biotype number of MDR strain of $R$. ornithinolytica. On the basis of changed biotype number after biofield treatment, new organism was identified as Klebsiella oxytoca. It is assumed that biofield treatment could be applied in biomedical health care system in future to improve the antimicrobial potency that enhance human well-being.

\section{Acknowledgement}

Authors gratefully acknowledged the whole team of PD Hinduja National Hospital and MRC, Mumbai, Microbiology Lab for their support.The generous support of Trivedi Science ${ }^{\mathrm{Tx}}$, Trivedi Master Wellness $^{\mathrm{Tw}}$ and Trivedi Testimonials is gratefully acknowledged.

\section{References}

1. Drancourt M, Bollet C, Carta A, Rousselier P (2001) Phylogenetic analyses of Klebsiella species delineate Klebsiella and Raoultellagen. nov., with description of Raoultella ornithinolytica comb. nov., Raoultella terrigena comb. nov. and Raoultella planticola comb. nov. Int J Syst Evol Microbiol 51: 925-932.
2. Kanki M, Yoda T, Tsukamoto T, Shibata T (2002) Klebsiella pneumoniae produces no histamine: Raoultella planticola and Raoultella ornithinolytica strains are histamine producers. Appl Environ Microbiol 68: 3462-3466.

3. Shaikh MM, Morgan M (2011) Sepsis caused by Raoultella terrigena. JRSM Short Rep 2: 49.

4. Chun S, Yun JW, Huh HJ, Lee NY (2014) Low virulence? Clinical characteristics of Raoultella planticola bacteremia. Infection 42: 899-904.

5. Hadano Y, Tsukahara M, Ito K, Suzuki J, Kawamura I, et al. (2012) Raoultella ornithinolytica bacteremia in cancer patients: Report of three cases. Intern Med 51: 3193-3195.

6. Haruki Y, Hagiya H, Sakuma A, Murase T, Sugiyama T, et al. (2014) Clinical characteristics of Raoultella ornithinolytica bacteremia: A case series and literature review. J Infect Chemother 20: 589-591.

7. Chun S, Yun JW, Huh HJ, Lee NY (2015) Clinical characteristics of Raoultella ornithinolytica bacteremia. Infection 43: 59-64.

8. Tseng SP, Wang JT, Liang CY, Lee PS, Chen YC, et al. (2014) First report of bla(IMP-8) in Raoultella planticola. Antimicrob Agents Chemother 58: 593-595.

9. Cunha BA (2001) Antibiotic side effects. Med Clin North Am 85: 149-185.

10. Rubik B (1994) Manual healing methods. Alternative medicine: expanding medical horizons, Washington, DC, US Government Printing Office, NIH Publication No. 094-066.

11. Thomas AH (2012) Hidden in plain sight: The simple link between relativity and quantum mechanics. Swansea, UK: CreateSpace Independent Publishing Platform.

12. Dale C (2009) The subtle body: An encyclopedia of your energetic anatomy. Boulder, CO: Sounds True, Inc.

13. Movaffaghi Z, Farsi M (2009) Biofield therapies: Biophysical basis and biological regulations. Complement Ther Clin Pract 15: 35-37.

14. Trivedi MK, Bhardwaj Y, Patil S, Shettigar H, Bulbule, A (2009) Impact of an external energy on Enterococcus faecalis [ATCC-51299] in relation to antibiotic susceptibility and biochemical reactions-an experimental study. J Accord Integr Med 5: 119-130.

15. Trivedi MK, Patil S (2008) Impact of an external energy on Staphylococcus epidermis [ATCC-13518] in relation to antibiotic susceptibility and biochemical reactions-an experimental study. J Accord Integr Med 4: 230-235.

16. Trivedi MK, Patil S (2008) Impact of an external energy on Yersinia enterocolitica [ATCC-23715] in relation to antibiotic susceptibility and biochemical reactions: An experimental study. Internet J Alternat Med 6.

17. Shinde V, Sances F, Patil S, Spence A (2012) Impact of biofield treatment on growth and yield of lettuce and tomato. Aust J Basis Appl Sci 6: 100-105.

18. Sances F, Flora E, Patil S, Spence A, Shinde V (2013) Impact of biofield treatment on ginseng and organic blueberry yield. Agrivita J Agric Sci 35: 22-29.

19. Lenssen AW (2013) Biofield and fungicide seed treatment influences on soybean productivity, seed quality and weed community. Agricultural Journal 8: 138-143.

20. Altekar N, Nayak G (2015) Effect of biofield treatment on plant growth and adaptation. J Environ Health Sci 1: 1-9.

21. Patil SA, Nayak GB, Barve SS, Tembe RP, Khan RR (2012) Impact of biofield treatment on growth and anatomical characteristics of Pogostemon cablin (Benth.). Biotechnology 11: 154-162.

22. Trivedi MK, Tallapragada RR (2008) A transcendental to changing metal powder characteristics. Met Powder Rep 63: 22-28.

23. Dabhade VV, Tallapragada RR, Trivedi MK (2009) Effect of external energy on atomic, crystalline and powder characteristics of antimony and bismuth powders. Bull Mater Sci 32: 471-479.

24. Trivedi MK, Tallapragada RR (2009) Effect of superconsciousness external energy on atomic, crystalline and powder characteristics of carbon allotrope powders. Mater Res Innovations 13: 473-480. 
Citation: $\quad$ Trivedi MK, Patil S, Harish S, Gangwar M, Jana S (2015) Biofield Treatment: An Alternative Approach to Combat Multidrug-Resistant Susceptibility Pattern of Raoultella ornithinolytica. Altern Integr Med 4: 193. doi:10.4172/2327-5162.1000193

Page 6 of 6

25. Fader RC, Weaver E, Fossett R, Toyras M, Vanderlaan J, et al. (2013) Multilaboratory study of the biomic automated well-reading instrument versus MicroScan WalkAway for reading MicroScan antimicrobial Susceptibility and identification panels. J Clin Microbiol 51: 1548-1554.

26. Mau N, Ross LA (2010) Raoultella ornithinolytica bacteremia in an infant with visceral heterotaxy. Pediatr Infect Dis J 29: 477-478.

27. Garcia-Lozano T, Pascual Pla FJ, Aznar Oroval E (2013) Raoultella ornithinolytica in urinary tract infections. Clinical and microbiological study of a series of 4 oncologic patients. Med Clin (Barc) 141: 138-139.

28. Tenover FC (2006) Mechanisms of antimicrobial resistance in bacteria. Am J Infect Control 119: S3-S10.

29. Alekshun MN, Levy SB (2007) Molecular mechanisms of antibacterial multidrug resistance. Cell 128: 1037-1050.

30. Al-Hulu SM, Al-Charrakh AH, Al-Saadi MAK (2009) Isolation and characterization of Raoultella ornithinolytica from clinical specimens in hilla city. Iraq Med J Babylon 7: 42-47.
31. Morais VP, Daporta MT, Bao AF, Campello MG (2009) Enteric fever-like syndrome caused by Raoultella ornithinolytica (Klebsiella ornithinolytica). J Clin Microbiol 47: 868-869.

32. Lucchetti G, de Oliveira RF, Goncalves JP, Ueda SM, Mimica LM, et al. (2013) Effect of Spiritist "passe" (Spiritual healing) on growth of bacterial cultures. Complement Ther Med 21: 627-632.

33. Hansen DS, Aucken HM, Abiola T, Podschun R (2004) Recommended test panel for differentiation of Klebsiella species on the basis of a trilateral interlaboratory evaluation of 18 biochemical tests. J Clin Microbiol 42: 3665-3669.

34. Trivedi MK, Patil S, Shettigar H, Gangwar M, Jana S (2015) Antimicrobial sensitivity pattern of Pseudomonas fluorescens after biofield treatment. J Infect Dis Ther 3: 222. 